\title{
DEFINING REQUIREMENTS FOR ENERGY EFFICIENCY IN MANUFACTURING
}

\author{
MicietA, B. \& BinAsova, V.
}

Abstract: The paper deals with definition of the requirements for achieving energy efficiency in manufacturing, which are essential to enhancement of productivity and profitability of future industrial processes. Within the development of sustainable production, it is necessary to pay particular attention to reducing energy consumption in manufacturing processes and increasing the energy efficiency of production systems. The modern techniques are designed to radically improve profitability, customer satisfaction, environmental and energy responsibility. In today's manufacturing environment there is a strong recognition of Energy Management as a significant source of both social responsibility and cost savings. Energy typically represents the single largest controllable cost in manufacturing, and is under constant scrutiny by all levels of management. This article presents research requirements that have been identified as important for manufacturing companies in energy efficient production.

Key words: manufacturing enterprise, energy efficiency, intelligent agent, sustainable development, reconfigurable manufacturing
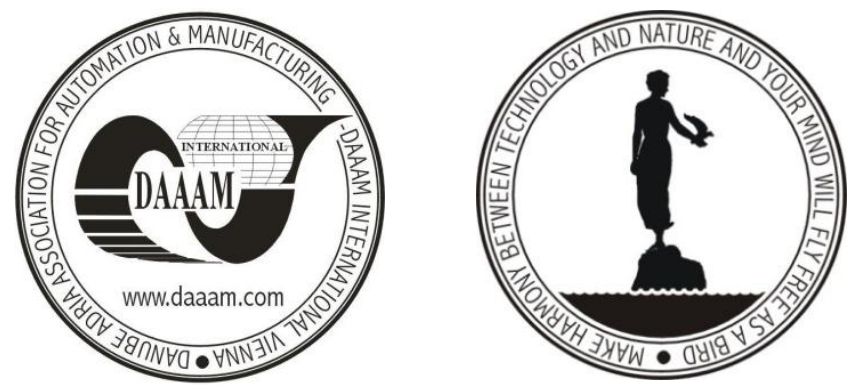

Authors' data: Prof. Ing. PhD. Micieta, B[ranislav]; Ing. Binasova, V[ladimira], Ing., University of Zilina, Univerzitna 1, 01 026, Zilina, Slovakia, branislav.micieta@fstroj.uniza.sk, vladimira.binasova@fstroj.uniza.sk

This Publication has to be referred as: Micieta, $\mathrm{B}$ [ranislav] \& Binasova, V[ladimira] (2013) Defining Requirements for Energy Efficiency in Manufacturing, Chapter 54 in DAAAM International Scientific Book 2013, pp. 887-894, B. Katalinic \& Z. Tekic (Eds.), Published by DAAAM International, ISBN 978-3-901509-94-0, ISSN 1726-9687, Vienna, Austria

DOI: 10.2507/daaam.scibook.2013.54 
Micieta, B. \& Binasova, V.: Defining Requirements for Energy Efficiency in Manu...

\section{Introduction}

Development of automation and intelligent manufacturing systems require energy-efficient design and its application. The proposed research is focused on analysis and optimization of tools for flexible energy use. Material flow integration should be developed, aiming at a holistic approach for resource management in process industries. The paper introduces the newly developed concept used as a tool for comparing and qualitatively assessing impact of efficient energy use.

\section{Definition of the Problem Statement of Energy efficiency in Manufacturing}

Basis for determining potential energy savings are energy audits which are also an important tool to assess the potential savings in the manufacturing enterprise. They should be a prerequisite for implementing energy saving measures. Energy efficiency law established duty to regular evaluates energy demand service in the industry (Machiba, 2009). That requires action plan of energy efficiency and sequence of energy performance cost reduction. Potential to improve the energy efficiency of industrial technologies in particular at the field of electric motors, pumps, fans and heating systems, but also more efficient light sources. In the next section will be described concept of energy efficiency oriented manufacturing (Fig. 1).

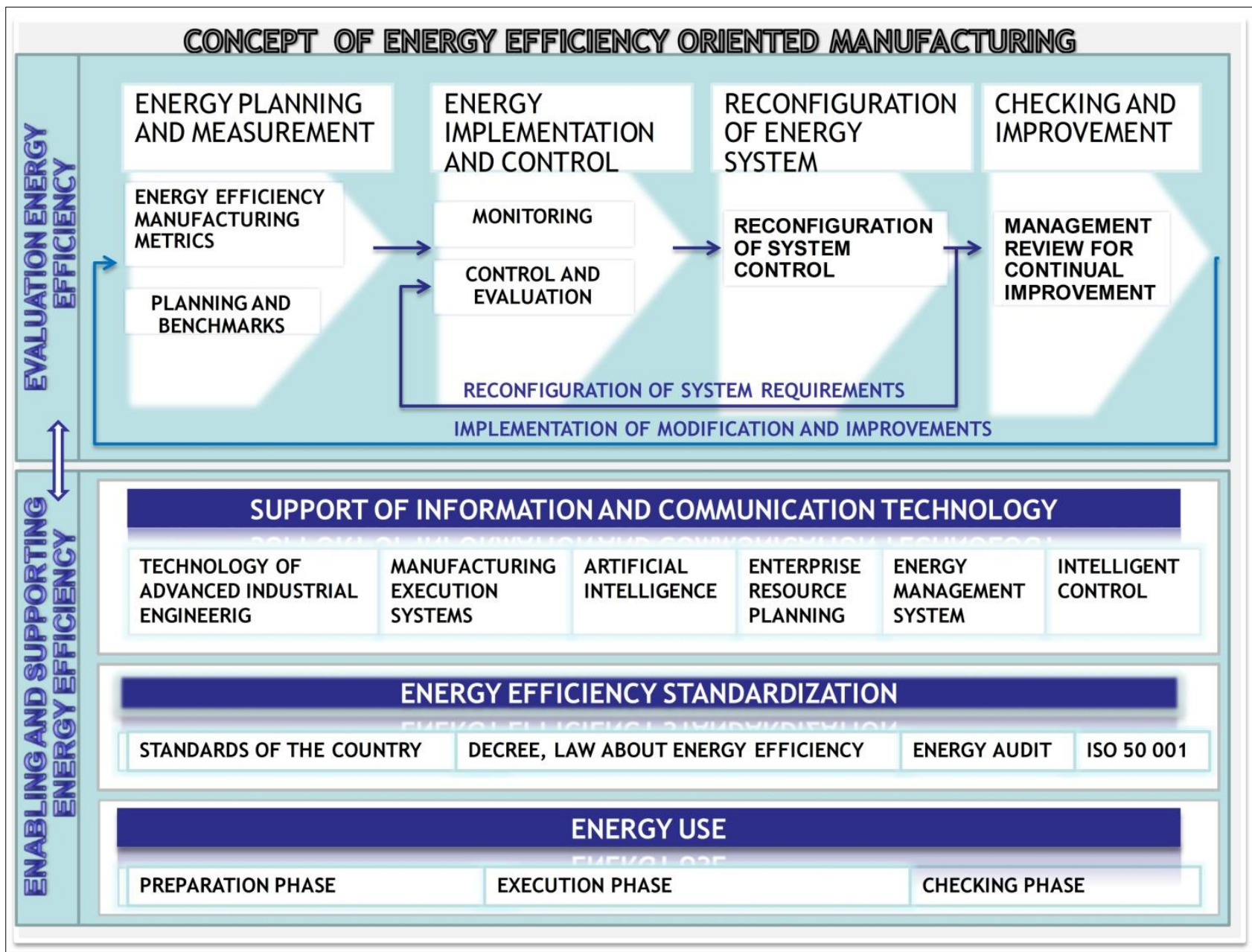

Fig. 1. Concept of energy efficiency oriented manufacturing 


\subsection{Energy planning and measurement}

Often, there is only rudimentary measuring equipment in place, particularly in smaller facilities. That should not be an impediment to starting an energy efficiency improvement project, however. More gauges, sensors and other equipment can be added as the energy management effort accelerates. In fact, early successes with energy-saving projects will provide strong justification for acquisition of new metering equipment.

Targets should be measurable and verifiable. To ensure that they are realistic, apply standards that indicate how much energy should be used for a particular application. Measure current performance against industry standards or calculated practical and theoretical energy requirements. Wherever possible, attempt to express the targets in relation to the unit of production.

In the industrial sector, activities such as the production process of a product can be described in either economic or physical terms resulting in either economic or physical indicators. When a target level is reached and the results level off, the target should be reset at a new, progressive value. Benchmarks of measures are for example:

- automatic control of energy consumption,

- benchmarks for similar equipment should be facilitated,

- benchmarks should be available, stating where other companies with the same challenges stand, in order to increase energy efficiency with the same process quality,

- best practices and the possibility to benchmark energy efficiency metrics should be given (Bunse, et al., 2010).

\subsection{Energy Implementation and Control}

The implementation of energy-saving projects should involve a coordinated, coherent set of projects linked together for the energy efficiency improvement program to be most effective. If several energy projects are contemplated, the interactions between them must also be considered. Monitoring and control of energy efficiency in manufacturing are important for energy management because more integration with systems using real-time data for operational monitoring and facilitating strategic decisions regarding energy efficiency and production line performance system to monitor energy consumption, or automation systems should include software to monitor processes and energy consumption.

Sensor technology for monitoring and transmitting production asset energy performance and sensor devices can measure energy efficiency and combine this information in an energy profile. A system could also make a profile of the machines, group them and allow a holistic plant control with regard to energy efficiency.

Responsibility for determining the energy performance indicators typically rests with the energy management representative and may involve other members of the energy team, as well as management. Resources to complete the energy performance indicators determination process are allocated by top management. 
The concept of energy performance includes energy use, energy efficiency and energy consumption. Thus the organization can choose between a wide range of energy performance activities. For example, the organization could reduce peak demand, utilize surplus or waste energy or improve the operations of its systems, processes or equipment.

\subsection{Reconfiguration of Energy System - Research of Gap Analysis}

Traditional manufacturing systems do not take into account many aspects: waste management, pollution, restoration and the reuse of used processes in production. Enterprises may on basis of environmental impact optimize the overall structure of control tasks, or expend cost of solving economic problems related to waste. Therefore, for the manufacturing systems is necessary to let them know autonomously react on a given topic.

Enterprises can strengthen its competitive advantage in sustainable manufacturing by the adoption of new, alternative materials that allow the conservation of resources. Closely related to resource conservation is recycling of materials. In some cases recycling processes themselves face both environmental and economic challenges.

Recyclability might be better incorporated into product design, to make disassembly of products at the end of their lifecycle easier. More easily recyclable and reusable materials could also be used. Improved process design and more efficient process technology may also contribute to improved resource efficiency. The requirements of reconfigurability of energy efficiency manufacturing system are shown in figure 2 .

The current performance of the manufacturing systems determines a clear definition of system boundaries (Geyer, 2010). The current systems are developed in accordance with cost metric, quality, personalization and time. Requirements for sustainability are considerably influencing behaviour of manufacturing systems and therefore it is necessary to consider the current performance deficiencies of existing systems. The newest development paradigm in field of adaptation to production requirements are reconfigurable manufacturing and assembly systems.

From the perspective of sustainability, the relevant objectives of reconfigurable manufacturing systems are:

- to reduce the wastes through the reuse of manufacturing resources,

- to reduce energy cost through the optimization of manufacturing processes and system reconfiguration (Botti \& Giret, 2008).

Even if an effective monitoring and control mechanism is in place, managers may have difficulties evaluating the impact and effects of energy efficiency improvement measures because of the lack of appropriate concepts for evaluation:

- evaluation of new or alternative concepts to increase efficiency considering the cost involved; this allows for transparency and identification of energy intensive components, e.g. in logistics systems, 
- new management concepts to derive appropriate energy efficiency improvement strategies,

- development of a cost calculation tool including 'resource and energy-cost', in order to make these costs transparent to the customer,

- assessment of the relationship between different manufacturing processes as improvement in one process could potentially negatively impact another part of the value stream with regard to energy efficiency.

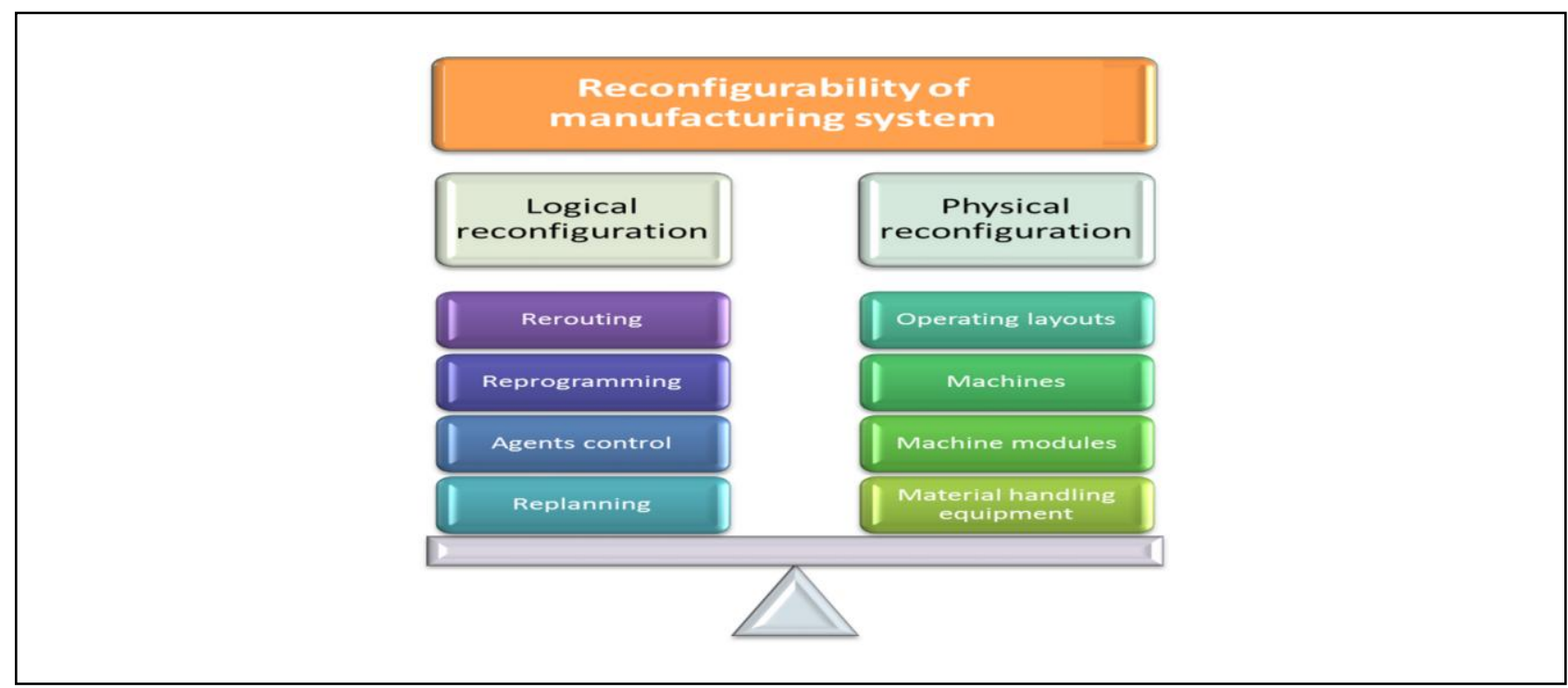

Fig. 2. Reconfigurability of energy efficiency manufacturing system

\subsection{Checking and Improvement}

In order to keep the energy management issue alive and to sustain interest, regular reporting to the management team is necessary. Energy management updates should be a permanent agenda item of regular operations management review meetings, just as quality, production, financial and environmental matters are. Results of the implemented project are reviewed, adjustments are made, conflicts are resolved and financial considerations are taken into account.

\subsection{Support of Information and Communication Technology}

The development of energy efficiency in manufacturing is one of the modern directions of supporting advanced industrial engineering, which pursues the objective of a change in business through new methods and approaches. Research on reducing the cost of energy consumption contributes significantly to increasing the energy efficiency of manufacturing processes to energy diversity through renewable energy sources.

The first such a significant trend that can be expected in energy efficiency in manufacturing is the development of information and communication technologies that will continue to influence all engineering disciplines, including the education of industrial engineers. The second direction is the artificial intelligence. In combination with robotics creates a space for the development of adaptive manufacturing, intelligent devices, and for the development of intelligent manufacturing systems. There are other directions of success in the future: 
- Energy efficiency in manufacturing will more and more move into consulting and service area at the expense of traditional production (research and development services, services related to the use of information and communication technology, management consulting, services related to enterprise management).

- Significant development of virtual reality and digital factory, their integration into design phase, doing process optimization in laboratory conditions and the following implementation in an industrial environment is very fast.

- Another change or direction is a question of a new form of cooperation.

- In the future, more use of operation research techniques to advanced of the Base PC models for the analysis of manufacturing and service problems.

- With the expansion of e-business, companies will need more advanced and accurate techniques for predicting the energy outputs. These techniques are based on computer simulation.

- The integration of man and his knowledge base in manufacturing processes.

\subsection{Energy Efficiency Standardization}

The first step in implementing an energy management program is the energy audit. It consists of documentary research, surveys (including interviews and observations) and analysis to determine where and how energy is used and may be lost. (Rahimifard et al., 2010). This procedure is summarized in three steps which represent the basic requirement of all energy audits:

- Evaluating the present energy consumption.

- Identifying of energy saving possibilities.

- Reporting audit.

\section{Technical Model of Energy Efficiency Improvement in Manufacturing - Results and Future Research}

Industry holds a large, highly concentrated potential for improving energy efficiency. Whose attractiveness for exploitation are shaped, not only by their technical merits, but also by site-specific energy markets, economic environments, business situations, managerial priorities and implementation barriers. Further, its energy efficiency can be improved by a wide variety of technical actions (Fig. 3). Furthermore industrial drivers constituted by rising and volatile energy prices, everstricter becoming legislations and increased customer awareness rise the attention to the research field (Rakyta, 2002). Holistic approaches to design and operate modern green production systems are required to cope with those challenges adequately. To analyze production systems with respect to economic, ecological and energy objectives, a specific set of data is necessary as an informational basis. The definition of input and output flows is a prerequisite to determine required economic, ecological and energy information on production systems. This also avoids possible problem shifting, e.g. when measures decrease one input variable but lead to an increase of another variable at the same time. Therefore, ecological and economic process models need to be combined to requirements for energy efficiency in manufacturing systems (Fig. 3). The integrated process model represents a description model of production system flows that allows capturing all relevant input and output flows and 
their quantitative values. The outcomes of the study incorporate a comparative overview of currently used methodologies, tools, indicators and practices in different sectors.

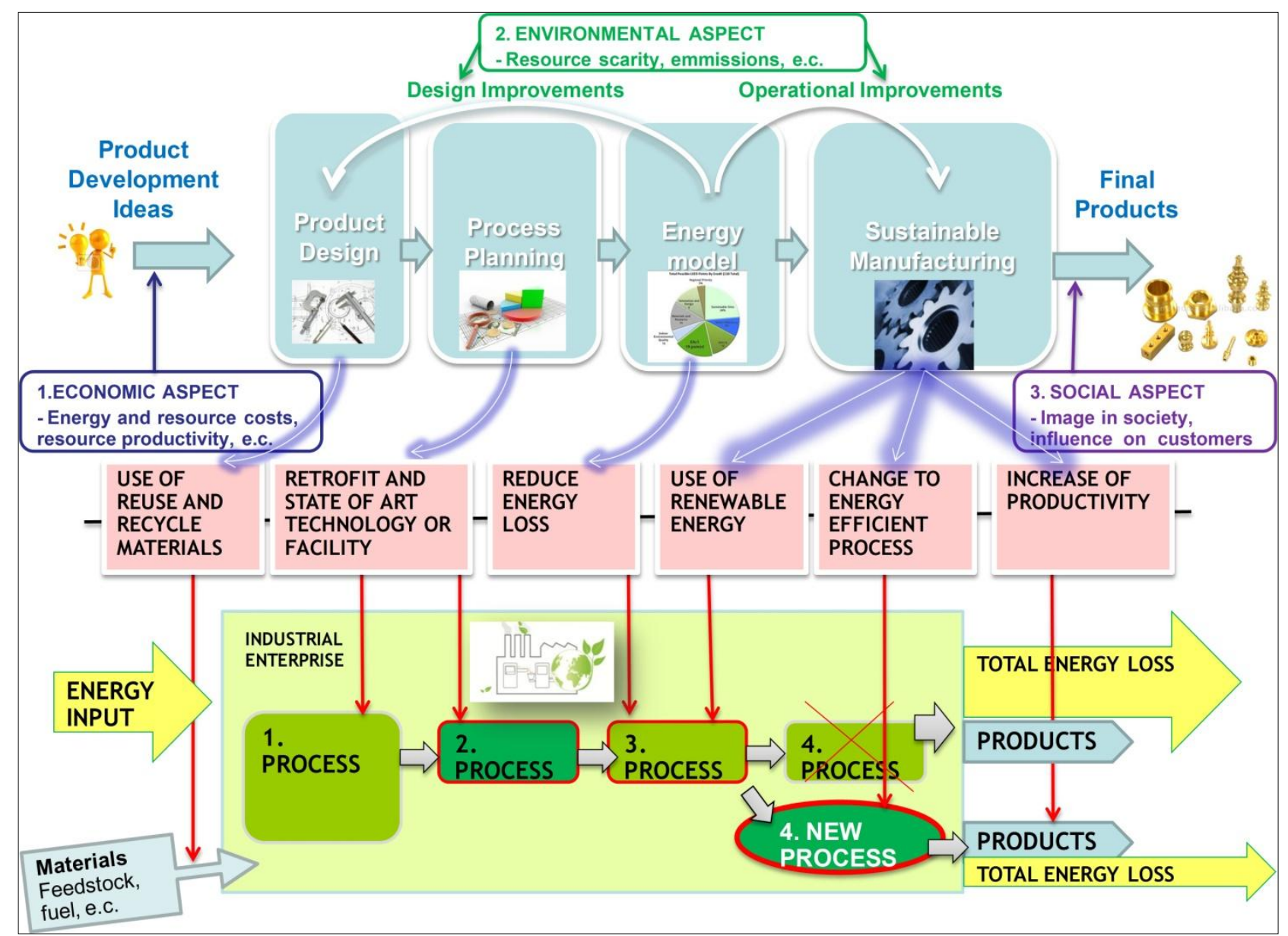

Fig. 3. Requirements for energy efficiency in manufacturing systems

Transferring this holistic view on a production plant leads to main partial systems that have to be considered: product design, process planning (with interlinked machines and personnel controlled through production management), energy model (the technical building services and the building shell). Having in mind the integrated process model, all involved input and output flows result in a complex control system with dynamic interdependencies between these subsystems via different internal and external influencing variables: as shown in Fig. 3. The research in this paper will contribute to create the value added activities and to develop the tool for comparing and qualitatively assessing impact on energy efficiency. However, looking at the ratio makes clear that increasing the output with no or proportionately less increase of the input energy is naturally also a legitimate way to improve energy efficiency. To correctly evaluate and compare the energy efficiency of production systems the consistent definition of the system boundaries as well as of the different possible output variables for example using masses instead of quantity are critical for practical application. The support action should involve a study across multiple sectors in the process industries considering all aspects of sustainability assessment along the whole product life cycles with regard to resource and energy efficiency. 
Micieta, B. \& Binasova, V.: Defining Requirements for Energy Efficiency in Manu...

\section{Conclusion}

Expected impact of concept described in this paper is e.g. reduction of production costs and time to market and optimisation (resource and energy efficiency). The results of implementation of this new concept of energy efficiency oriented manufacturing will lead to future research plans. There is a need to search for opportunities, not only in undertaking energy saving technical actions, but also in introducing of reconfiguration of system requirements. There is a need for further study of, for example, selected case studies, for actual implementation of reconfiguration of energy system. There is also a need for a deeper look into policy packages - how the components complement one another, and how policy coherence is maintained to ensure overall efficacy and cost efficiency in sustainable manufacturing as the philosophy of eliminating waste within a process, and place them in a form of continuous flow energy consumption to better meet customer demand. Specific challenge is an implementation of innovative technologies for resource and energy efficiency. It will require a consistent sustainability assessment across sectors and along the value chains. There is a need to increase the European knowledge base related to applied sustainability assessment tools, methodologies, indicators and to overcome the bottlenecks of further development in the process industry.

\section{Acknowledgements}

This article was prepared by within the project VEGA no. 1/0701/12 named as Research on the use of low-cost automation and artificial intelligence in the process of recording stereoscopic.

\section{References}

Botti, V.; Giret, A. (2008). A multi-agent methodology for holonic manufacturing systems, Springer, ISBN 978-1-84800-309-5, London

Bunse, K.; Sachs, J. \& Vodicka, M. (2010). Evaluating energy efficiency improvements in manufacturing processes, In: Advances in Production Management Systems, New Challenges, New Approaches, Vallespir, B., Alix, T. (Eds.), pp. 19-26, Springer, ISBN 978-3-642-16358-6, Boston

Geyer, A. (2010). The challenge of sustainable manufacturing, Available from: http://citeseerx.ist.psu.edu/viewdoc/download?doi=10.1.1.200.5742\&rep=rep1\&type =pdf Accessed: 2013-08-23

Machiba, T. (2009). Sustainable Manufacturing and Eco-Innovation, Available from: http://www.oecd.org/sti/inno/43423689.pdf, Accessed: 2013-08-23

Rahimifard, S.; Seow, Y. \& Childs, T. (2010). Minimising Embodied Product Energy to support energy efficient manufacturing, Available from: http://www.sciencedirect.com/science/article/pii/S0007850610000491 Accessed: 2013-08-23

Rakyta, M. (2002). Udrzba ako zdroj produktivity,( Administration of a source productivity) Georg, ISBN 80-68324-3-3, Zilina 